\title{
Effects of continuous endotracheal-laryngopharynx topical anesthesia on the general anesthetic requirements during surgery
}

\author{
Runqiao Fu ${ }^{1}$, Lihong Wang ${ }^{1}$, Xiaofeng Peng ${ }^{1}$, Wangyan Yang ${ }^{1}$, Mianrong Xue ${ }^{1}$, Li Yan ${ }^{2}$ \\ ${ }^{1}$ Department of Anesthesiology, Chui Yangliu Hospital, Tsinghua University, Beijing, China; ${ }^{2}$ Department of Pathophysiology, Institute of Basic \\ Medical Sciences, Peking Union Medical College, Chinese Academy of Medical Sciences, Beijing, China \\ Correspondence to: Runqiao Fu. Department of Anesthesiology, Chui Yangliu Hospital, Tsinghua University, No. 2 South Street, Chuiyangliu, \\ Chaoyang District, Beijing 100022, China. Email: furunqiao@aliyun.com.
}

\begin{abstract}
The purpose of this study was to investigate the general anesthetic requirements in patients with continuous endotracheal-laryngopharynx topical anesthesia using medicine injecting endotracheal tube during surgery. A total of 78 patients with American Society of Anesthesiologists (ASA) physical status I-II were randomly divided into test group and control group. After anesthesia, patients were injected by 1.5 $\mathrm{mL}$ of $1 \%$ Tetracaine for topical anesthesia, and later injected similarly at hourly intervals during surgery while patients in control group were non-injected. There was no statistical significance in values of SBP, DBP, MAP, HR and plasma concentrations of E, NE and Cor at same time point between the two groups during operation $(\mathrm{P}>0.05)$. There was no statistical significance in value of $\mathrm{BIS}$ at $\mathrm{T}_{0}-\mathrm{T}_{5}$ between the two groups $(\mathrm{P}>0.05)$. However, value of BIS at $\mathrm{T}_{6}$ in test group was significantly higher than that in control group $(69.7 \pm 2.1$ vs. $58.6 \pm 2.3, \mathrm{P}<0.01)$. Doses of sevoflurane, propofol sufentanil and cisatracurium used up in test group decreased by $12.3 \%(\mathrm{P}<0.01) ; 12.7 \%(\mathrm{P}<0.01) ; 14.5 \%(\mathrm{P}<0.01)$ and $4.9 \%(\mathrm{P}>0.05)$ than those in control group, respectively. Continuous endotracheal-laryngopharynx topical anesthesia using $1 \%$ Tetracaine via medicine-injecting endotracheal tube can significantly decrease general anesthetic requirements of surgery.
\end{abstract}

Keywords: Medicine-injecting endotracheal tube; Tetracaine; continuous endotracheal-laryngopharynx topical anesthesia; general anesthetic requirements

Submitted Jan 03, 2020. Accepted for publication Jul 03, 2020.

doi: $10.21037 /$ tcr-20-169

View this article at: http://dx.doi.org/10.21037/tcr-20-169

\section{Introduction}

General anesthesia refers to the temporary inhibition of central nervous system when anesthetics are inhaled into the body through respiratory tract, intravenous or intramuscular injection. The clinical manifestations are loss of consciousness, loss of general pain, forgetting, reflex inhibition and skeletal muscle relaxation. The degree of inhibition of central nervous system is related to the concentration of drugs in the blood, and can be controlled and regulated. The general anesthesia methods commonly used in clinic are inhalation anesthesia, intravenous anesthesia and combined anesthesia.

Combined anesthesia is the main trend in anesthesiology to reduce stress response of the surgical patients and to reduce general anesthetic requirements for better recovery, which has been written into guide of Enhanced Recovery after Surgery (ERAS) (1). For example, peripheral nerve block combined general anesthesia, epidural blockade combined general anesthesia, and Dexmedetomidine assisted general anesthesia can reduce general anesthetic requirements or adverse effects, which are beneficial for the recovery of general anesthesia (2-6). Recently, it has been reported that endotracheal topical anesthesia shows a tendency to reduce general anesthetic requirements (7-9). Based on a small sample observation, endotracheal continuous topical anesthesia does have the tendency to 


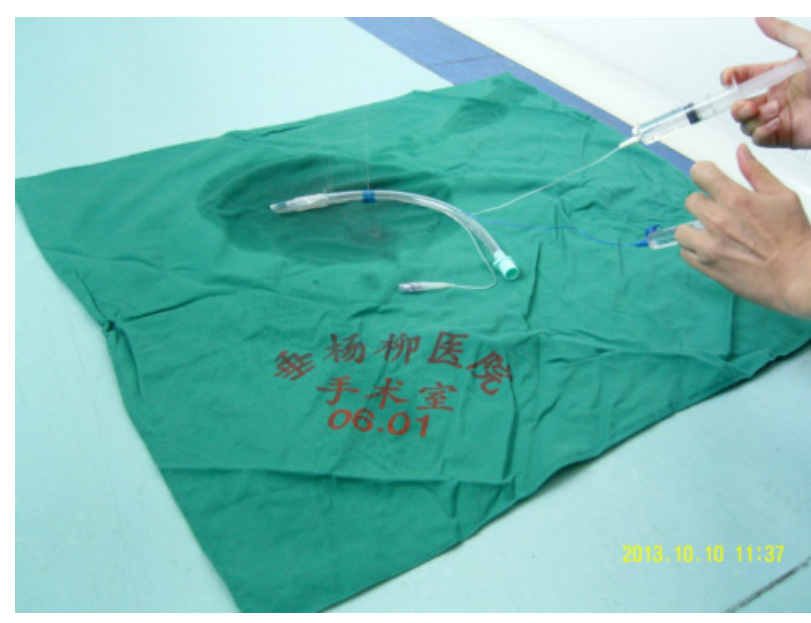

Figure 1 Supraglottic and subglottic medicine-injecting endotracheal tube.

reduce general anesthetic requirements, but the statistical differences are not significant (9). Therefore, the purpose of this study was to investigate the general anesthetic requirements in patients with continuous endotracheallaryngopharynx topical anesthesia using the medicineinjecting endotracheal tube during surgery through relatively big subject size.

\section{Surgical process}

\section{Patients}

The study was conducted in a single center. This prospective, observational study was conducted between January 2016 and December 2018 in the Chui Yangliu Hospital, Tsinghua University. A total of 78 patients with well-controlled medical conditions [American Society of Anesthesiologists (ASA) physical status I-II] who underwent laparotomy, gastrointestinal surgery and pelvic operation elective general anesthesia were recruited. They aged 26-62 years' old. Patients with body mass index (BMI) of $23-30 \mathrm{~kg} / \mathrm{m}^{2}$ were included without gender limitation. Those patients with upper respiratory infections, hypertension, heart disease, diabetes, or organ dysfunctions including liver and kidney were excluded. They were randomly divided into injecting group (test group, $\mathrm{n}=36$ ) and non-injecting group (control group, $\mathrm{n}=36$ ).

The study was conducted in accordance with the Declaration of Helsinki (as revised in 2013). The study was approved by institutional/regional/national ethics/ committee/ethics board of Chui Yangliu Hospital, Tsinghua University (No.: 20170305) and informed consent was taken from all the patients.

\section{Material selection}

The "medicine-injecting endotracheal tube between supraglottic and subglottic area" was used in our study (Figure 1, hereinafter referred as injecting endotracheal tube). The characteristic of this tube was that there were two thin tubes inside the wall (similar to the tubes for injecting air into airbags). Its proximal end was for injecting medicine. The distal end connected two small injection sacs on the tube wall. One was $1 \mathrm{~cm}$ from the airbag (white), and the other was $5 \mathrm{~cm}$ from the airbag (blue) with $4 \mathrm{~cm}$ in the middle. Each inject sac had four spray pores at different direction. Topical anesthetic reached sacs through medicineinjecting endotracheal tube and was evenly sprayed on the surrounding tissues to exert topical anesthesia effect. While performing tracheal intubation, the two sacs were right at supraglottic and subglottic area, namely endotracheal and laryngopharynx. The blue sac was the supraglottic/ laryngopharynx injection sac, which was also an indication for the depth of intubation.

\section{Anesthesia}

After being admitted into the operation room (OR), the patients were injected by $8 \mathrm{~mL} / \mathrm{kg}$ of sodium lactate ringer's injection through venous route and connected to BeneView T8. Systolic blood pressure (SBP), diastolic blood pressure (DBP), mean arterial pressure (MAP) and heart rate (HR) were monitored by radial arterial connection. Rapid sequence induction for anesthesia was performed with intravenous injection of Midazolam $0.04 \mathrm{mg} / \mathrm{kg}$, Cisatracurium $0.25 \mathrm{mg} / \mathrm{kg}$, Sufentanil $0.2 \mu \mathrm{g} / \mathrm{kg}$ and Propofol $2 \mathrm{mg} / \mathrm{kg}$. Then, respiration was manually controlled for $150 \mathrm{~s}$. Tracheal intubation was performed through visible laryngoscope exposure via mouth (7.5-8.0 ID). The patients in test group were injected $1.5 \mathrm{~mL}$ of $1 \%$ Tetracaine $(0.5 \mathrm{~mL}$ for laryngopharynx and $1 \mathrm{~mL}$ for endotracheal) by assistant through a supraglottic tube and a subglottic tube. The patients in control group was not injected. Tracheal tube was then fixed and Darger Primus connected for ventilation. Tidal volume was $8-10 \mathrm{~mL} / \mathrm{kg}$. Frequency was 10-12 times/min. Inhalation $v s$. exhalation 
was 1 vs. 1.5. Stable oxygen flow rate was $1.5 \mathrm{~L} / \mathrm{min}$. $\mathrm{P}_{\mathrm{ET}}$ $\mathrm{CO}_{2}$ was $30-35 \mathrm{mmHg}$. In addition, the patients in test group were injected with Tetracaine for topical anesthesia at an interval of $1 \mathrm{~h}$ and the patients in control group were not injected.

Inhalation of small dose of Sevoflurane $(\leq 0.8 \mathrm{Vol} \%)$ was used, and Propofol 4-6 mg/(kg.h), Sufentanil 0.1-0.2 $\mu \mathrm{k} /$ $(\mathrm{kg} \cdot \mathrm{h})$ and Cisatracurium was injected intravenously via close-loop target-controlled infusion [Veryark, maintaining TOF at $0 \%$ and automatically giving drug when stimulation count showed a (T1)] to maintain 45-60 of bispectral index (BIS) and variations of BP and HR lower $30 \%$ of base value. Six percent Hetastarch (200/0.5) and sodium lactate ringer's injection were intraoperatively used to maintain blood volume. Blood transfusion was performed when $\mathrm{Hb}$ was lower than $7 \%$ and the volume of urine was maintained above $1 \mathrm{~mL} /(\mathrm{kg} . \mathrm{h})$. Sevoflurane was stopped on $30 \mathrm{~min}$, and Propofol, Sufentanil and Cisatracurium were stopped 15 min prior to the end of surgery. Fresh gas (oxygen) flow was stable and no other methods were adopted to accelerate or decelerate the wash-out of sevoflurane. Regular intravenous injection of Atropine $0.5 \mathrm{mg}$, Neostigmine $1 \mathrm{mg}$ and Flumazenil $1 \mathrm{mg}$ were as antagonist.

\section{Sampling and testing}

The patients admitted to OR staying calm and stable. At T0 (base value before anesthesia), T1 (before incision), T2 (during operation $15 \mathrm{~min}), \mathrm{T} 3$ (60 min), T4 (90 min), T5 (120 min) and T6 (the end of operation). SBP, DBP, MAP and HR were recorded. $2.5 \mathrm{~mL}$ of radial artery blood was collected and stored in a test tube (EDTA anticoagulation) at $-25^{\circ} \mathrm{C}$. The concentration of epinephrine (E), norepinephrine (NE) and cortisone (Cor) in the two groups were collectively observed in 3 months by using ELISA method at the pathology and physiology lab of the Institute of Basic Medical Sciences of the Chinese Academy of Medical Sciences.

Dosage of drugs used for general anesthesia was calculated after the operation. Calculation of the inhaled anesthetics: several data of open reading value (DragerVapor $2000 \mathrm{Vol} \%$ ) $\times$ time the reading value lasted (min) (4). It was the total inhaled anesthetics for each patient. The fresh gas (oxygen) flow rate was stable at $1.5 \mathrm{~L} / \mathrm{min}$ and the waste gas analyzed by sampling escaped the breathing circle. Postoperative follow-up was carried out to inquire the patients whether they experienced adverse effects including intraoperative awareness, postoperative uneasiness in the throat and aspiration of vomit.

\section{Statistical analysis}

Software SPSS 20.0 (International Business Machines, corp., Armonk, NY, USA) was used to analyze the data. Measurement data was expressed as average value \pm standard deviation $(\bar{x} \pm S D)$ (the data were normally distributed). Counting data was expressed as a percentage. The values between groups were assessed by using $t$-test. The values in the same group were assessed by using variance analysis. Counting data was assessed by using Chi-square test. $\alpha=0.05$ was the standard value and the difference was statistical significance when $\mathrm{P}<0.05$.

\section{Results}

\section{Clinical characteristics of the patients}

All patients met the criteria and were included in our study. There was no withdrawal or dropout. The clinical characteristics were summarized in Table 1. We found that there was no significant difference in age, BMI, operative time, blood loss volume, infusion, RCS infusion and urine volume between the two group $(\mathrm{P}>0.05$, Table 1).

\section{Circulation maintain}

During the operation, the values of SBP, DBP, MAP and HR in the two groups were stable. In addition, the values of SBP, DBP, MAP and HR at T1 were significantly reduced in comparison with those at $\mathrm{T} 0$ in the two groups $(\mathrm{P}<0.01$, Table 2). However, the values of SBP, DBP, MAP and HR at T6 were significantly increased when compared to those at $\mathrm{T} 0$ in the two groups $(\mathrm{P}<0.05$ or $\mathrm{P}<0.01$, Table 2). The mean values at each time point in test group were similar to those in control group $(\mathrm{P}>0.05$, Table 2).

\section{The changes of E, NE and Cor at each time points during the operation in the two groups}

There was no significant difference in values of $\mathrm{E}, \mathrm{NE}$, and Cor at each time point during the operation in test group and control group $(\mathrm{P}>0.05$, Table 3). Similarly, there was no significant difference in values of $\mathrm{E}, \mathrm{NE}$, and Cor between T6 and T0 in the two groups $(\mathrm{P}>0.05$, Table 3). However, 
Table 1 The basic clinical characteristics of patients in the two groups $(\bar{x} \pm S D)$

\begin{tabular}{lll}
\hline Groups & Test group $(\mathrm{n}=36)$ & Control group $(\mathrm{n}=36)$ \\
\hline Age $($ years old $)$ & $36.2 \pm 7.1$ & $37.7 \pm 6.2$ \\
Gender $(\mathrm{M} / \mathrm{F})$ & $13 / 23$ & $12 / 24$ \\
Height $(\mathrm{cm})$ & $168.6 \pm 4.4$ & $167.3 \pm 5.2$ \\
Weight $(\mathrm{kg})$ & $66.3 \pm 6.6$ & $66.1 \pm 6.3$ \\
BMI $\left(\mathrm{kg} / \mathrm{m}^{2}\right)$ & $26.3 \pm 2.0$ & $26.6 \pm 2.1$ \\
Operative time $(\mathrm{min})$ & $200.5 \pm 15.2$ & $198.7 \pm 15.5$ \\
Tetracaine dose $(\mathrm{mg})$ & $60.0 \pm 0$ & $60.0 \pm 0$ \\
Blood loss $(\mathrm{mL})$ & $343.4 \pm 23.6$ & $348.4 \pm 25.2$ \\
Infusion $(\mathrm{mL})$ & $1,585.7 \pm 103.6$ & $1,545.3 \pm 114.9$ \\
RCS infusion $(\mathrm{mL})$ & $470.9 \pm 23.5$ & $488.4 \pm 21.8$ \\
Urine $(\mathrm{mL})$ & $225.5 \pm 22.4$ & $211.3 \pm 21.5$ \\
\hline
\end{tabular}

Table 2 The changes of BP and HR in the two groups $(\bar{x} \pm S D)$

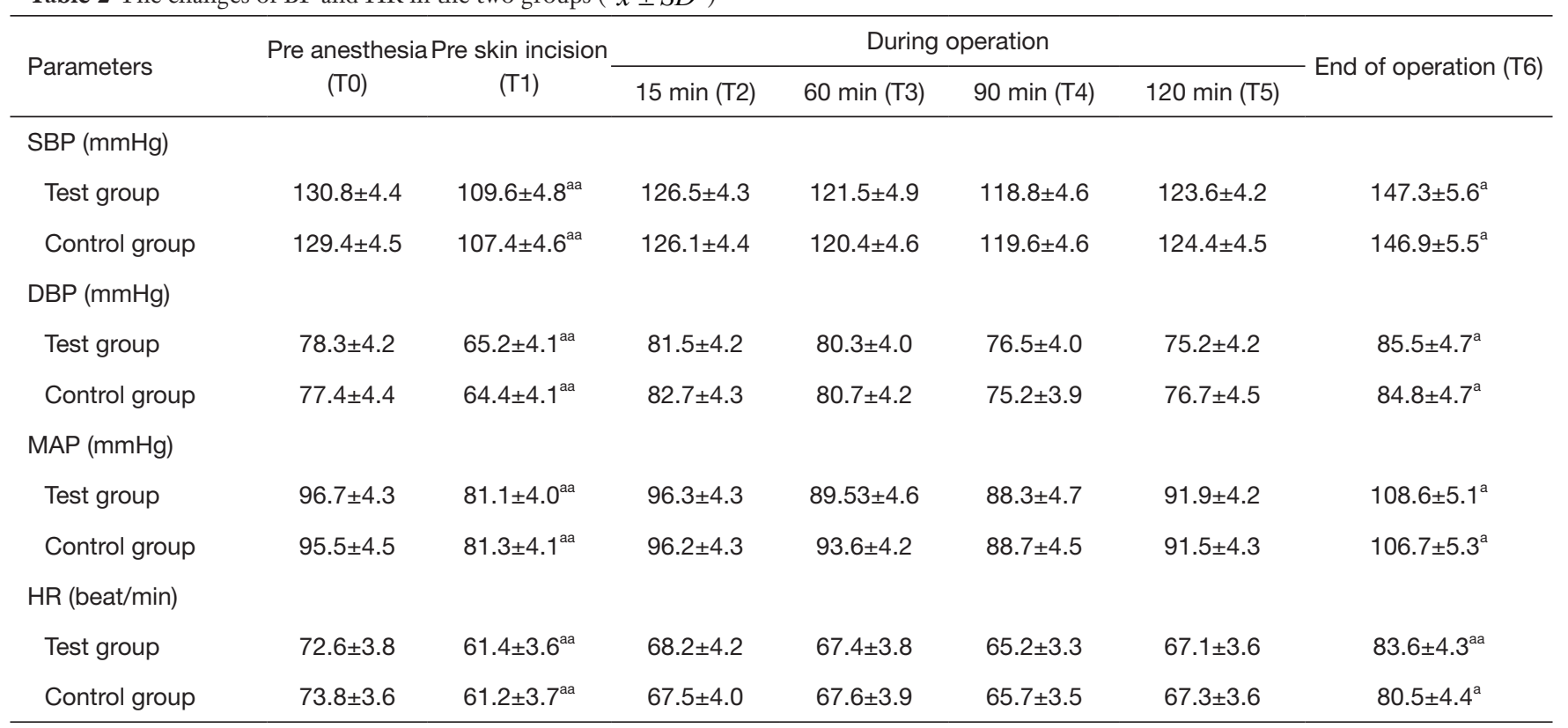

${ }^{\mathrm{a}}, \mathrm{P}<0.05$; ${ }^{\text {aa }}, \mathrm{P}<0.01$, vs. T0 in the control group or test group. SBP, systolic blood pressure; DBP, diastolic blood pressure; MAP, mean arterial pressure; $\mathrm{HR}$, heart rate.

the values of $\mathrm{E}, \mathrm{NE}$, and Cor at T1-T5 in the two groups were obviously decreased in comparation with those values at T0 $(\mathrm{P}<0.05$, Table 3$)$.

\section{Changes of BIS}

There was no significant difference in the values of BIS at T0-T5 between the two groups $(\mathrm{P}>0.05$, Table 4$)$. On the contrary, the value of BIS at T6 in test group was significant increased when compared to that in control group $(\mathrm{P}<0.05$, Table 4). Besides, the values of BIS at T1-T6 in the two groups were markedly decreased in comparison with those at T0 $(\mathrm{P}<0.01$, Table 4$)$.

\section{Drug doses for general anesthesia}

Drug dose for general anesthesia: compared with the control group, the test group's dosage of sevoflurane, 
Table 3 The changes of $\mathrm{E}, \mathrm{NE}$ and Cor of patients in the two groups $(\bar{x} \pm S D)$

\begin{tabular}{|c|c|c|c|c|c|c|c|}
\hline \multirow{2}{*}{ Parmeters } & \multirow{2}{*}{$\begin{array}{c}\text { Pre anesthesia } \\
\text { (T0) }\end{array}$} & \multirow{2}{*}{$\begin{array}{l}\text { Pre skin incision } \\
\text { (T1) }\end{array}$} & \multicolumn{4}{|c|}{ During operation } & \multirow{2}{*}{$\begin{array}{c}\text { End of } \\
\text { operation (T6 }\end{array}$} \\
\hline & & & $15 \min (\mathrm{T} 2)$ & $60 \min ($ T3) & $90 \min (\mathrm{T} 4)$ & $120 \min (\mathrm{T} 5)$ & \\
\hline \multicolumn{8}{|l|}{$E(p g / m L)$} \\
\hline Test group & $150.2 \pm 11.5$ & $109.5 \pm 7.8^{\mathrm{aa}}$ & $115.4 \pm 9.3^{\text {aa }}$ & $115.3 \pm 8.7^{\mathrm{aa}}$ & $118.7 \pm 7.8^{\mathrm{aa}}$ & $120.6 \pm 10.7^{\text {aa }}$ & $155.1 \pm 9.8$ \\
\hline Control group & $151.6 \pm 12.6$ & $107.8 \pm 7.5^{\mathrm{aa}}$ & $116.5 \pm 8.9^{\text {aa }}$ & $113.4 \pm 7.9^{\mathrm{aa}}$ & $115.7 \pm 8.4^{\mathrm{aa}}$ & $118.3 \pm 9.9^{\text {aa }}$ & $150.8 \pm 9.1$ \\
\hline Test group & $485.4 \pm 30.2$ & $366.8 \pm 25.3^{\text {aa }}$ & $384.7 \pm 25.7^{\mathrm{aa}}$ & $388.4 \pm 24.6^{\mathrm{aa}}$ & $390.5 \pm 26.6^{\mathrm{aa}}$ & $395.2 \pm 28.1^{\text {aa }}$ & $498.3 \pm 31.1$ \\
\hline Control group & $486.2 \pm 31.4$ & $360.6 \pm 24.5^{\text {aа }}$ & $385.4 \pm 24.4^{\text {aа }}$ & $378.5 \pm 25.8^{\text {aa }}$ & $380.9 \pm 25.3^{\text {aа }}$ & $390.7 \pm 27.4^{\text {aa }}$ & $475.5 \pm 29.8$ \\
\hline \multicolumn{8}{|l|}{ Cor (ng/mL) } \\
\hline Test group & $160.5 \pm 8.5$ & $104.7 \pm 5.3^{\mathrm{aa}}$ & $112.5 \pm 4.4^{\mathrm{aa}}$ & $123.4 \pm 4.7^{\text {aa }}$ & $118.3 \pm 4.0^{\mathrm{aa}}$ & $116.9 \pm 4.6^{\mathrm{aa}}$ & $150.6 \pm 5.4$ \\
\hline
\end{tabular}

${ }^{\mathrm{a}}, \mathrm{P}<0.05 ;{ }^{\text {aa }}, \mathrm{P}<0.01$, vs. T0 in the control group or test group. E, epinephrine; NE, norepinephrine; Cor, cortisone.

Table 4 The changes BIS of patients in the two groups $(\bar{x} \pm S D)$

\begin{tabular}{|c|c|c|c|c|c|c|c|}
\hline \multirow{2}{*}{ Groups } & \multirow{2}{*}{$\begin{array}{l}\text { Pre anesthesia } \\
\text { (T0) }\end{array}$} & \multirow{2}{*}{$\begin{array}{c}\text { Pre skin incision } \\
\text { (T1) }\end{array}$} & \multicolumn{4}{|c|}{ During operation } & \multirow{2}{*}{ End of operation (T6) } \\
\hline & & & $15 \min (T 2)$ & $60 \min ($ T3) & $90 \min (\mathrm{T} 4)$ & $120 \min (\mathrm{T} 5)$ & \\
\hline Test group & $98.4 \pm 0.7$ & $47.7 \pm 1.2^{\mathrm{aa}}$ & $48.5 \pm 1.4^{\text {aa }}$ & $52.7 \pm 1.7^{\text {aa }}$ & $52.4 \pm 1.5^{\mathrm{aa}}$ & $54.1 \pm 1.4^{\text {aa }}$ & $69.7 \pm 2.1^{\mathrm{aa}, \mathrm{bb}}$ \\
\hline Control group & $98.5 \pm 0.6$ & $47.5 \pm 1.6^{\mathrm{aa}}$ & $48.4 \pm 1.5^{\mathrm{aa}}$ & $51.3 \pm 1.3^{\mathrm{aa}}$ & $51.5 \pm 1.2^{\mathrm{aa}}$ & $53.5 \pm 1.5^{\mathrm{aa}}$ & $58.6 \pm 2.3^{\mathrm{aa}}$ \\
\hline
\end{tabular}

${ }^{\text {aa }}, \mathrm{P}<0.01$, vs. T0 in the control group or test group. ${ }^{\text {bb }}, \mathrm{P}<0.01$, vs. control group.

Table 5 The drug doses of patients in the two groups $(\bar{x} \pm S D)$

\begin{tabular}{lcccc}
\hline Anesthetics & Test group & Control group & Reduction rate (\%) & t value \\
\hline Sevoflurane (Vol\%·min) & $120.8 \pm 21.6$ & $137.8 \pm 20.3$ & $12.3 \%$ & 2.584 \\
Propofol $(\mathrm{mg})$ & $740.6 \pm 13.2$ & $848.2 \pm 12.5$ & $12.7 \%$ & 2.793 \\
Sufentanil $(\mu \mathrm{g})$ & $29.5 \pm 0.8$ & $34.5 \pm 0.9$ & $14.5 \%$ & 2.852 \\
Cisatracurium $(\mathrm{mg})$ & $88.4 \pm 2.4$ & $93.0 \pm 1.3$ & $4.9 \%$ & 1.265 \\
\hline
\end{tabular}

propofol, sufentanil and cisatracurium reduced by $12.3 \%$ $(\mathrm{P}<0.01), 12.7 \%(\mathrm{P}<0.01), 14.5 \%(\mathrm{P}<0.01)$ and $4.9 \%$ $(\mathrm{P}>0.05)$ respectively (Table 5$)$.

\section{Adverse reactions during and after operation}

According to postoperative follow-up, there were no adverse reactions of intra-operative awareness, hoarseness, choking or aspiration in patients in the two groups.

\section{Discussion}

Deep anesthesia is associated with instability of vital signs during operation and increased postoperative long- 
term mortality rate (10). Especially in elderly patients, the maintained depth of anesthesia was advised with BIS changes from 40-55 to 45-60 (11). As muscle relaxants block the somatic nerve reflex during general anesthesia, patient is immobilized and the sympathetic nerve reflex activity is still present or even more obvious. For example, the endotracheal tube inserted into the trachea always stimulates the trachea, pharynx and larynx wall, especially in the surgery on the head, face, neck and chest, which are close to the airway and cause more airway friction $(12,13)$. It prompts anesthesiologists to add anesthetics or nonanesthetics (e.g., $\alpha$ or $\beta$ receptors' blockers) to control stress response to maintain hemodynamic stability. The former is not conducive to postoperative recovery and long-term benefits, and the latter is palliatives and difficult to be mastered. Therefore, it is theoretically best to use a partial measure to eliminate catheter irritation. Chen et al. reported that the dosage of isoflurane in the EMLA (compound lidocaine cream, $2.5 \%$ lidocaine and $2.5 \%$ propitocaine) coated endotracheal tube in test group (30 cases) was $13 \%$ lower than that in control group (30 cases) (7). It is reported that the use of ENLA (same to Chen) decreased sufentanil requirements during extubation in thyroidectomy under general anesthesia (12). We recently reported that continuous endotracheal-laryngopharyngeal topical anesthesia decreased sevoflurane by $3.4 \%$, propofol by $8.3 \%$ and sufentanil by $4.1 \%$ in patients undergoing general anesthesia (9). Although there was no significant statistical difference, each drug showed a decreasing trend. And the main reason for no significant statistical difference was that the number of cases was small (each group had 20 cases) and the operative site was far from the airway (lower limb surgery). Therefore, this study has expanded the number of cases and is not limited to lower limb surgery, which makes the experimental design more reasonable.

Anesthetists often conduct cricothyroid puncture to inject $1 \%$ Tetracaine $2 \mathrm{~mL}$ to make the patient cough so that the drug can be sprayed in the trachea and throat for topical anesthesia. Otolaryngologists often use a spray bottle to spray Tetracaine on the throat for topical anesthesia. The method in this study was the same as our previous method (9), $1 \%$ Tetracaine $1.5 \mathrm{~mL}(1 \mathrm{~mL}$ for endotracheal and $0.5 \mathrm{~mL}$ for laryngopharynx) for topical anesthesia was repeated hourly. The average time from the beginning of anesthesia to the end of operation was $200.5 \pm 15.2 \mathrm{~min}$ in test group and $198.7 \pm 15.5 \mathrm{~min}$ in control group, respectively. Within $4 \mathrm{~h}$, only four injections of topical anesthetics were given, with a total of $60 \mathrm{mg}$ in each patient. The maximum dose of Tetracaine was 40-60 mg for topical anesthesia once administration. The dosage was safely judged because there was no cardiovascular abnormality, the recovery process was stable, and there was no adverse reaction after waking up.

At present, BIS, blood pressure and heart rate are still dominant in judging the depth of anesthesia and the degree of stress reaction $(11,14)$, and catecholamine in plasma can be determined if possible. In this study, BIS, blood pressure and heart rate stability were used as targeted anesthesia to maintain blood pressure and heart rate in two groups with similar levels of epinephrine, norepinephrine and cortisol in blood. No case was conscious during the surgery according to postoperative follow-up, which indicated that the depth of anesthesia and stress response were properly controlled in both groups. Sevoflurane, Propofol, Sufentanil and Cisatracurium were respectively decreased by $12.3 \%$, $12.7 \%, 14.5 \%$ and $4.9 \%$ in test group under continuous endotracheal-laryngopharyngeal topical anesthesia than those in control group. We understood that topical anesthesia inhibited the endotracheal and laryngopharynx stimulus response of the catheter reducing the drug usage. This was similar to what Chen reported (7), which used lidocaine cream (EMLA) to coat the surface of the catheter to reduce the irritation effect of the catheter on the airway mucosa. However, their method was one-off so that the anesthesia effect was limited. Our results suggested that long-term topical anesthesia was suitable for long-term intubated general anesthesia surgery, especially for patients with catheter who can also continue to use it after sent to ICU.

At the end of operation, the value of BIS in test group was significantly higher than that in control group, which was the reason why the patients in test group recovered more quickly with less general anesthetic dosage. Combined with the effect of airway topical anesthesia on the quality of recovery during peri-extubation period $(8,12,15)$, the hemodynamics in test group was more stable, less cough reaction, less restlessness of limbs, strong tolerance to catheter and command coordination, which greatly increased the safety of extubation and accelerated the patient to leave the OR.

To sum up, combined with the concept of compound anesthesia in enhanced recovery after surgery (ERAS) of modern surgery, continuous endotrachealpharyngolaryngeal topical anesthesia was carried out with medicine-injecting tracheal catheter during the whole operation. The method is simple and feasible, which can stabilize the hemodynamics and reduce the dosage of 
general anesthetics, and is conducive to patients' smooth recovery and leave the operating room faster. The method is worth promoting. However, it is need to be further studied about the pharmacokinetics and pharmacodynamics of topical anesthetics after absorption and the possible toxic effects after prolonged use.

\section{Acknowledgments}

Funding: This study was approved by the financial support from Beijing Capital Research Foundation of Medical Developments (No. 2009-3215).

\section{Footnote}

Conflicts of Interest: All authors have completed the ICMJE uniform disclosure form (available at http://dx.doi. org/10.21037/tcr-20-169). The authors have no conflicts of interest to declare.

Ethical Statement: The authors are accountable for all aspects of the work in ensuring that questions related to the accuracy or integrity of any part of the work are appropriately investigated and resolved. The study was conducted in accordance with the Declaration of Helsinki (as revised in 2013). The study was approved by institutional/ regional/national ethics/committee/ethics board of Chui Yangliu Hospital, Tsinghua University (No.: 20170305) and informed consent was taken from all the patients.

Open Access Statement: This is an Open Access article distributed in accordance with the Creative Commons Attribution-NonCommercial-NoDerivs 4.0 International License (CC BY-NC-ND 4.0), which permits the noncommercial replication and distribution of the article with the strict proviso that no changes or edits are made and the original work is properly cited (including links to both the formal publication through the relevant DOI and the license). See: https://creativecommons.org/licenses/by-nc-nd/4.0/.

\section{References}

1. Zhao YP, Xiong LZ. Chinese Expert Consensus and Path Management Guidelines of Enhanced Recovery After Surgery (2018). Chinese Journal of Practical Surgery 2018;38:1-20.

2. Wang Y, Zhang GM. Analysis on the Effect of General Anesthesia Combined with Epidural Block on Post- operative Cognitive Disorder for Patients with Gastric Cancer Undergoing Laparoscopic Radical Operation. J Med Res 2018;47:118-20.

3. Xiao YM, Li YH, Gao ZX. Application of general anesthesia combined with ultrasound-guided paravertebral nerve block in patients undergoing thoracoscopic and laparoscopic esophagectomy. J Clin Anesthesiol 2018;34:529-33.

4. Zhang LN, Ji ZR, Cao XZ, et al. Clinical observation of femoral nerve block combined with the general anesthesia in elderly patients undergoing total knee arthroplasty. Journal of Chinese Physician 2013;15:1366-8.

5. Harsoor SS, Rani DD, Lathashree S, et al. Effect of intraoperative dexmedetomidine infusion on sevoflurane requirement and blood glucose levels during entropyguided general anesthesia. J Anaesthesiol Clin Pharmacol 2014;30:25-30.

6. Dundar N, Kus A, Gurkan Y, et al. Analgesia nociception index (ani) monitoring in patients with thoracic paravertebral block: a randomized controlled study. J Clin Monit Comput 2018;32:481-6.

7. Chen L, Wang Y, Zhu T, et al. Trachea surface anesthesia or/ and epidural block reduces isoflurane requirements in general anesthesia. J Clin Anesthesiol 2007;23:99-101.

8. Tang WX, Wang SD. Mucosa surface anesthesia combined intravenous remifentanil for patients undergoing endoscopic sinus surgery. J Clin Anesthesiol 2011;27:1086-8.

9. Fu RQ, Wang W, Peng XF, et al. Effects of continuous endotracheal-laryngopharynx topical anesthesia on the general anesthetic requirements during surgery. Perioperative Safety and Quality Assurance 2018;2:145-9.

10. Monk TG, Saini V, Weldon BC, et al. Anesthetic management and one-year mortality after moncardiac surgery. Anesth Analg 2005;100:4-10.

11. Yue Y. Anesthesia depth and postoperative longterm mortality. Journal of Capital Medical University 2013;34:669-72.

12. Sang NE, Qu G, Zhang XH, et al. Topical anesthetic effects of compound lidocaine cream coated endotracheal tube to prevent cough and agitation during extubation in thyroidectomy under general anesthesia. Basic Clin Med 2015;35:86-9.

13. Hu ZH, Zhang JL, Tong MJ, et al. Endotracheal tube with injecting medicine can restrain stress reaction of patients after uvulopalatopharyngoplasty. J Clin Anesthesiol 2016;32:980-3.

14. Nakhli MS, Kahloul M, Guizani T, et al. Intravenous 
lidocaine as adjuvant to general anesthesia in renal surgery. Libyan J Med 2018;13:1433418.

15. Fang $\mathrm{P}, \mathrm{Zong} \mathrm{Z}, \mathrm{Lu} \mathrm{Y}$, et al. Effect of topical ropivacaine

Cite this article as: Fu R, Wang L, Peng X, Yang W, Xue M, Yan L. Effects of continuous endotracheal-laryngopharynx topical anesthesia on the general anesthetic requirements during surgery. Transl Cancer Res 2020;9(8):4968-4975. doi: $10.21037 /$ tcr-20-169 on the response to endotracheal tube during emergence from general anesthesia: a prospective randomized doubleblind controlled study. BMC Anesthesiol 2018;18:134. 